\title{
Prevalence of Myclobutanil Resistance and Difenoconazole Insensitivity in Populations of Venturia inaequalis
}

Sara M. Villani, Section of Plant Pathology and Plant-Microbe Biology, School of Integrative Plant Science, Cornell University, Geneva, NY 14456; Alan R. Biggs, Kearneysville Tree Fruit Research and Education Center, West Virginia University, Kearneysville 25443; Daniel R. Cooley, Department Plant, Soil, and Insect Science, University of Massachusetts, Amherst 01003; and Jessica J. Raes and Kerik D. Cox, Section of Plant Pathology and Plant-Microbe Biology, School of Integrative Plant Science, Cornell University

\begin{abstract}
Villani, S. M., Biggs, A. R., Cooley, D. R., Raes, J. J., and Cox, K. D. 2015. Prevalence of myclobutanil resistance and difenoconazole insensitivity in populations of Venturia inaequalis. Plant Dis. 99:1526-1536.

Demethylation inhibitors (DMIs) are a class of single-site fungicides with high levels of protective and curative efficacy against Venturia inaequalis, the causal agent of apple scab. To determine the prevalence of resistance to the DMI fungicide myclobutanil, 3,987 single-lesion conidial $V$. inaequalis isolates from 141 commercial, research, and baseline orchard populations were examined throughout New England, the mid-Atlantic, and the Midwest from 2004 to 2013. Of these orchard populations, 63\% had practical resistance, $13 \%$ had reduced sensitivity, and $24 \%$ were sensitive to myclobutanil. A sensitivity baseline for the recently introduced DMI fungicide difenoconazole was established to make comparisons with myclobutanil sensitivity in orchard populations. The mean effective concentration of difenoconazole at which mycelial growth was inhibited

by $50 \%\left(\mathrm{EC}_{50}\right)$ was determined to be $0.002 \mu \mathrm{g} \mathrm{ml}^{-1}$ for 44 baseline isolates of $V$. inaequalis. From 2010 to 2013, 1,012 isolates of $V$. inaequalis from 37 of the 141 orchard populations above were screened for sensitivity to difenoconazole. In all, 1 orchard population had reduced sensitivity to difenoconazole, while the remaining 36 orchard populations were sensitive to the fungicide. In field experiments, difenoconazole demonstrated high levels of apple scab control on mature apple fruit, despite the fact that the population of $V$. inaequalis had practical resistance to difenoconazole. Although our results indicate widespread resistance to myclobutanil but not difenoconazole, due to the propensity for crosssensitivity among DMI fungicides, growers with myclobutanil resistance should be cautious when using difenoconazole for disease management.
\end{abstract}

Apple scab, caused by the fungal pathogen Venturia inaequalis (Cooke) G. Winter, is among the most prevalent and economically important diseases in commercial apple orchards in regions with temperate climates worldwide (MacHardy 1996; MacHardy et al. 2001). The absence of durable apple scab resistance in the majority of commercially desired cultivars often mandates more than 10 fungicide applications each season to successfully manage the disease (Köller and Wilcox 2001; Lesniak et al. 2011; MacHardy 1996). Highly effective single-site fungicides such as the guanidines (1950s), sterile demethylation inhibitors (DMIs) (1980s), and quinone outside inhibitors (QoIs) (1990s) have enhanced our ability to manage a number of phytopathogenic fungi, including $V$. inaequalis. Of these fungicides, the DMIs have been especially attractive to growers because of their strong pre- and postinfection activity. Even 10 years after their introduction for use in commercial apple orchards in the United States, DMI fungicides had curative activity up to $96 \mathrm{~h}$ following an infection event (Beckerman et al. 2015).

DMI fungicides are a class of broad-spectrum, systemic compounds with high levels of activity against several plant-pathogenic fungi, including those that cause apple scab, rusts, and powdery mildews (Schnabel and Jones 2001). Historically, the DMI were most effective when used following infection events (Köller and Wilcox 1999; O'Leary et al. 1987; Schwabe et al. 1984; Szkolnik 1981), because they arrest fungal growth during and after infection by inhibiting demethylation at the $14-\alpha$ carbon of lanosterol, a sterol intermediate of ergosterol, which is essential for hyphal growth. Although DMI fungicides are considered a medium risk for resistance by the fungicide resistance action committee (Stenzel 2014), the highly specific nature and repetitive use of DMI fungicides has led

Corresponding author: K. D. Cox; E-mail: kdc33@cornell.edu

Accepted for publication 16 March 2015.

http://dx.doi.org/10.1094/PDIS-01-15-0002-RE

(c) 2015 The American Phytopathological Society to their diminished efficacy and widespread resistance in key apple production regions in North America (Braun and McRae 1992; Hildebrand et al. 1988; Jobin and Carisse 2007; Köller et al. 1997; Villani and Cox 2011).

In the history of apple scab management in the United States, the loss of one fungicide class due to resistance concerns has led to heavy reliance on the most recently registered alternative single-site fungicide class. For example, resistance to dodine by the 1970s was directly followed by dependence on and subsequent rapid onset of resistance to benzimidazoles (Jones 1981). Subsequently, the DMI fungicides and the more recently registered QoI fungicides became the industry standard for both protective and postinfection management of apple scab. As early as 1985, roughly 10 years after DMI fungicides were first applied commercially, individual $V$. inaequalis isolates were found to have reduced sensitivity to eight DMI fungicides (Stanis and Jones 1985).

Practical resistance, defined as greatly diminished levels of disease control following proper fungicide application under field conditions (Köller 1991; Villani and Cox 2014), was first reported for DMI in populations of $V$. inaequalis collected from a research orchard in Nova Scotia (Hildebrand et al. 1988) and later in a commercial orchard in Michigan (Köller et al. 1997). Since the initial reports, DMI fungicide resistance in populations of $V$. inaequalis has been documented in Virginia (Marine et al. 2007), Pennsylvania (Pfeufer and Ngugi 2012), and Indiana (Chapman et al. 2011). Although individual isolates of $V$. inaequalis collected from New York orchards have previously been found to be resistant to the DMI fungicide fenarimol (Köller and Wilcox 1999), practical resistance to more heavily relied upon DMI fungicides in populations of $V$. inaequalis from the state has not been documented.

Since 2004, the authors have received increasing reports of practical resistance to myclobutanil (Nova 40W/Rally 40WSP) and fenarimol (Rubigan/Vintage SC) from apple growers in the mid-Atlantic and Northeastern United States. The failure of myclobutanil and other DMIs to provide acceptable levels of apple scab control has forced growers to modify their disease management programs. With limited single-site fungicide alternatives, producers are increasingly 
relying on multisite protectant fungicides (i.e., captan and mancozeb) to manage apple scab. Protectant fungicides must be applied more frequently, have little to no postinfection activity, and are relatively ineffective (in comparison with DMI) in controlling apple powdery mildew (Köller et al. 1997), which should be managed during the same time as apple scab in the northeastern United States. In 2009, several DMI fungicides marketed previously in Europe were registered for management of apple scab in North America. These fungicides included difenoconazole and fenbuconazole, which have been found to have higher in vitro intrinsic activity (Pfeufer and Ngugi 2012) and greater efficacy in the field (Cox et al. 2013) against $V$. inaequalis compared with myclobutanil.

The early reports of DMI control failures in the mid-Atlantic and the northeastern U.S. apple production regions, accompanied by the advent of newly released DMI fungicides for managing apple scab, prompted us to conduct an investigation of DMI fungicide resistance in $V$. inaequalis populations. The specific objectives of our study were to (i) determine the extent of myclobutanil resistance in orchard populations of $V$. inaequalis across the mid-Atlantic, the Midwest, and the northeastern United States from 2004 to 2013; (ii) establish baseline in vitro sensitivities for the DMI fungicide difenoconazole in $V$. inaequalis; (iii) evaluate and compare in vitro difenoconazole sensitivity for populations of $V$. inaequalis with practical resistance or sensitivity to myclobutanil; and (iv) determine the effect of myclobutanil or difenoconazole applications in monitored populations of $V$. inaequalis with practical resistance or sensitivity to myclobutanil.

\section{Materials and Methods}

Collection of $\boldsymbol{V}$. inaequalis isolates. From 2004 to 2013, isolates of $V$. inaequalis were collected from 141 individual apple orchards throughout the northeastern United States. The orchards examined represent the range of DMI fungicide use practices and nearly all of the major apple production operations in the region, which consisted of 14 research, 119 commercial, and 8 baseline orchards. Some orchard populations were tested for DMI sensitivity because the grower had reported unsatisfactory control of apple scab that resulted in the appearance of apple scab symptoms following application of a DMI fungicide. However, nearly half of the orchard populations evaluated for sensitivity to myclobutanil were collected prior to local concerns over DMI performance by using bait trees or leaving trees unsprayed. Baseline orchards were designated as such if the orchard had never been exposed to any single-site fungicide classes, including the anilinopyrimidines, benzimidazoles, DMI, guanidines, QoI, or succinate dehydrogenase inhibitors.

Isolates from each orchard were obtained by arbitrarily collecting 50 to 100 young, fully expanded leaves that contained isolated young, sporulating primary apple scab lesions throughout the orchard. From each leaf collection, 50 leaves were selected and one individual lesion representing a single-spore infection event (Köller et al. 2004; MacHardy and Gadoury 1989) from each of those leaves was phenotyped for sensitivity to the DMI fungicide myclobutanil using microscopy-aided mycelial relative growth (RG) assays, as previously described and validated (Frederick et al. 2014; Köller et al. 2004; Villani and Cox 2014). Briefly, the single-conidial lesion isolates (referred to as "isolates" throughout the remainder of the manuscript) were removed using a sterile cork borer ( $5 \mathrm{~mm}$ in diameter), placed in $1.2 \mathrm{ml}$ of sterile distilled water, and shaken for $60 \mathrm{~s}$ to dislodge conidia from the lesion. The leaf discs were promptly removed and $100-\mu$ l suspensions of $10^{3}$ to $10^{4} \mathrm{~V}$. inaequalis conidia $\mathrm{ml}^{-1}$ were evenly distributed on potato dextrose agar (PDA; Difco Laboratories) amended with streptomycin sulfate $\left(50 \mu \mathrm{g} \mathrm{ml}^{-1}\right)$, chloramphenicol $\left(50 \mu \mathrm{g} \mathrm{ml}^{-1}\right)$, and analytical grade myclobutanil (Sigma Aldrich) dissolved in acetone (Sigma Aldrich) at a discriminatory dose of $0.1 \mu \mathrm{g}$ $\mathrm{ml}^{-1}$, as suggested by Köller et al. $(1991,1997)$. Isolates were incubated at $22^{\circ} \mathrm{C}$ for 6 days, and mycelial growth of five randomly selected microcolonies originating from single spores was determined by measuring microcolony diameter or germ-tube length (for spores with greatly inhibited growth) using a SPOT Idea digital camera (with the SPOT Imaging Basic software package; Diagnostic Instruments Inc.) attached to an Olympus SZX12 stereoscope (Olympus America Inc.).
The in vitro sensitivity response for each isolate in each of the 141 orchard populations was expressed as mean percent relative growth (\%RG), as previously described (Frederick et al. 2014; Köller et al. 1991; Smith et al. 1991). Each orchard population was subsequently characterized as having or lacking practical resistance to myclobutanil by comparing the distribution of sensitivity responses (mean \%RG) for each orchard population in question to standards in which practical resistance or sensitivity to myclobutanil had already been verified. The practical resistance status of both the standard resistant orchard and the standard sensitive orchard was determined directly by examining fungicide application practices for each standard orchard and assessing the development of apple scab symptoms following application of Rally 40WSP or Nova 40W (myclobutanil; Dow Agrosciences). In 2011, orchard 61 had 5.8\% incidence of apple scab on mature 'Jerseymac' fruit at harvest following four applications of Rally 40WSP and was used as the sensitive standard population. In 2010, orchard 26 had $45.3 \%$ incidence of apple scab at harvest on mature 'McIntosh' fruit following four applications of Rally 40WSP and was used as the resistant standard population. For both the sensitive standard and the resistant standard orchard populations, 50 young, fully expanded leaves that contained isolated young, sporulating primary apple scab lesions were collected throughout the orchard and in vitro sensitivity to myclobutanil was determined as described above. Comparisons of isolate sensitivity distributions to the standard orchard populations were made using the nonparametric Kolmogorov-Smirnov (K-S) two sample test in SAS (version 9.3; SAS Institute).

Using a K-S two-sample test, the practical resistance classification was determined for each of the 141 orchards by comparing the distribution of isolate myclobutanil responses for each orchard population (the "test orchard") to sensitivity distributions of both the resistant and sensitive standards (Frederick et al. 2014). Initially, the probability that the distribution of myclobutanil sensitivity responses for a given test orchard was different from the distribution of the resistant standard orchard $\left(\mathrm{P}_{\mathrm{T}}=_{\mathrm{R}}\right)$ or different from the distribution in myclobutanil sensitivity of the sensitive standard orchard $\left(\mathrm{P}_{\mathrm{T}}=\mathrm{S}\right)$ was determined. The outcome of the two probability tests was then used to classify the orchard population in one of four scenarios. For instance, if a given test orchard had $\mathrm{P}_{\mathrm{T}}={ }_{\mathrm{R}}<0.05$ and $\mathrm{P}_{\mathrm{T}}={ }_{\mathrm{S}} \geq 0.05$, the sensitivity distribution of the orchard in question would be significantly different from the resistant standard but not from the sensitive standard; thus, the test orchard would be classified as "sensitive". Alternatively, if a given test orchard had $\mathrm{P}_{\mathrm{T}}={ }_{\mathrm{R}} \geq 0.05$ and $\mathrm{P}_{\mathrm{T}}={ }_{\mathrm{S}}<0.05$, the sensitivity distribution of the orchard in question would be significantly different from the sensitive standard but not from the resistant standard and, thus, the test orchard would be classified as "resistant". In cases where the sensitivity distribution for a test orchard was not significantly different from the standard resistant orchard and the standard sensitive orchard $\left(\mathrm{P}_{\mathrm{T}}={ }_{\mathrm{R}} \geq 0.05\right.$ and $\left.\mathrm{P}_{\mathrm{T}}={ }_{\mathrm{S}} \geq 0.05\right)$, the population in the test orchard would be considered "reduced sensitive" to myclobutanil. Finally, the distribution of a test orchard population may be significantly different from the sensitive standard and the resistant standard. Such a situation may happen when the distribution of the RG of isolates in the test orchard population was significantly greater than the resistant standard orchard or when the distribution of the RG of isolates in the test orchard population was significantly lower than the sensitive standard orchard. In such situations, an orchard would be classified as "resistant" or "sensitive", respectively. Although sensitivity classifications were based on the distribution of isolate sensitivities within a population of $V$. inaequalis, the mean \%RG was reported for each orchard population to facilitate comparisons between orchards. Thus, in some instances, sensitivity classifications (i.e., resistant and reduced sensitive), which were determined using the K-S statistical analysis, will have overlapping mean \% RG values. In all cases, it is important to understand that classification of a test orchard only implies how its population would behave in regards to that of the standards for the purpose of discussing risk of product failure and the prevalence of resistance to DMI. It is not meant to be used to emphatically indicate product failure regardless of host and environment. 
Table 1. Sensitivity classification, percent relative growth, isolation year, and collection location from which Venturia inaequalis populations were surveyed for myclobutanil resistance

\begin{tabular}{|c|c|c|c|c|c|c|c|}
\hline Orchard $^{\mathbf{a}}$ & Classification $^{b}$ & $n$ & $\% \mathrm{RG}^{\mathrm{c}}$ & Pr $>$ Ksa resistant ${ }^{d}$ & Pr $>$ Ksa sensitive ${ }^{d}$ & Year & State \\
\hline 1 & Resistant & 30 & $131.6 \pm 13.8$ & 0.0020 & $<0.0001$ & 2005 & New York \\
\hline 3 & Resistant & 32 & $96.9 \pm 5.9$ & 0.0003 & $<0.0001$ & 2009 & New York \\
\hline 5 & Resistant & 31 & $94.5 \pm 8.0$ & $<0.0001$ & $<0.0001$ & 2005 & New York \\
\hline 6 & Resistant & 27 & $58.4 \pm 5.9$ & 0.4125 & 0.0439 & 2007 & Massachusetts \\
\hline 8 & Resistant & 30 & $67.7 \pm 5.7$ & 0.6984 & 0.0011 & 2007 & New York \\
\hline 9 & Resistant & 30 & $111.8 \pm 9.0$ & 0.0004 & $<0.0001$ & 2006 & New York \\
\hline 12 & Resistant & 30 & $113.7 \pm 11.0$ & 0.0003 & $<0.0001$ & 2007 & New York \\
\hline 16 & Resistant & 30 & $87.4 \pm 6.6$ & 0.0714 & $<0.0001$ & 2007 & New Hampshire \\
\hline 18 & Resistant & 29 & $86.1 \pm 4.7$ & 0.0646 & $<0.0001$ & 2006 & Massachusetts \\
\hline 19 & Resistant & 26 & $96.4 \pm 3.6$ & $<0.0001$ & $<0.0001$ & 2013 & Vermont \\
\hline 20 & Resistant & 30 & $95.8 \pm 6.9$ & 0.0016 & $<0.0001$ & 2006 & New York \\
\hline 21 & Resistant & 16 & $80.0 \pm 7.0$ & 0.1268 & $<0.0001$ & 2007 & Maine \\
\hline 24 & Resistant & 30 & $66.5 \pm 3.9$ & 0.6243 & 0.0006 & 2007 & Maine \\
\hline 25 & Resistant & 28 & $65.3 \pm 5.6$ & 0.5924 & 0.0016 & 2006 & Massachusetts \\
\hline 26 & Resistant & 36 & $67.7 \pm 3.4$ & 1.0000 & 0.0055 & 2010 & New York \\
\hline 27 & Resistant & 22 & $61.0 \pm 6.5$ & 0.2757 & 0.0245 & 2006 & Rhode Island \\
\hline 31 & Resistant & 30 & $85.0 \pm 8.0$ & 0.0456 & 0.0003 & 2007 & New York \\
\hline 34 & Resistant & 19 & $75.1 \pm 7.1$ & 0.4401 & 0.0002 & 2007 & New York \\
\hline 35 & Resistant & 31 & $75.0 \pm 4.3$ & 0.1869 & $<0.0001$ & 2005 & Ohio \\
\hline 37 & Resistant & 35 & $96.4 \pm 2.2$ & $<0.0001$ & $<0.0001$ & 2013 & New York \\
\hline 38 & Resistant & 21 & $72.7 \pm 7.5$ & 0.3866 & 0.0029 & 2008 & Rhode Island \\
\hline 39 & Resistant & 30 & $75.7 \pm 6.7$ & 0.3701 & 0.0008 & 2007 & Rhode Island \\
\hline 42 & Resistant & 30 & $69.3 \pm 5.1$ & 0.0015 & 0.5806 & 2006 & Massachusetts \\
\hline 43 & Resistant & 31 & $64.1 \pm 5.8$ & 0.069 & 0.002 & 2012 & Maine \\
\hline 45 & Resistant & 30 & $66.0 \pm 3.6$ & 0.3415 & $<0.0001$ & 2006 & New York \\
\hline 47 & Resistant & 38 & $113.5 \pm 13.1$ & 0.0006 & $<0.0001$ & 2008 & Rhode Island \\
\hline 48 & Resistant & 47 & $89.7 \pm 3.7$ & 0.0010 & $<0.0001$ & 2008 & West Virginia \\
\hline 49 & Resistant & 30 & $83.7 \pm 3.8$ & 0.0308 & $<0.0001$ & 2006 & New York \\
\hline 53 & Resistant & 30 & $108.2 \pm 11.3$ & 0.0105 & $<0.0001$ & 2007 & West Virginia \\
\hline 54 & Resistant & 17 & $109.5 \pm 8.8$ & 0.0017 & $<0.0001$ & 2008 & New York \\
\hline 55 & Resistant & 30 & $84.0 \pm 8.8$ & 0.2610 & 0.0003 & 2006 & Massachusetts \\
\hline 56 & Resistant & 30 & $79.6 \pm 5.8$ & 0.0701 & $<0.0001$ & 2006 & Massachusetts \\
\hline 57 & Resistant & 30 & $76.2 \pm 4.9$ & 0.2849 & $<0.0001$ & 2007 & New York \\
\hline 59 & Resistant & 30 & $94.8 \pm 7.1$ & 0.0078 & $<0.0001$ & 2007 & Connecticut \\
\hline 60 & Resistant & 30 & $77.8 \pm 3.1$ & 0.0701 & $<0.0001$ & 2007 & New York \\
\hline 63 & Resistant & 22 & $82.9 \pm 5.0$ & 0.0471 & $<0.0001$ & 2007 & New York \\
\hline 64 & Resistant & 30 & $92.4 \pm 8.2$ & 0.0123 & $<0.0001$ & 2006 & New York \\
\hline 67 & Resistant & 30 & $69.8 \pm 6.4$ & 0.4642 & 0.0010 & 2007 & Massachusetts \\
\hline 68 & Resistant & 30 & $74.9 \pm 5.1$ & 0.1926 & $<0.0001$ & 2005 & New York \\
\hline 70 & Resistant & 30 & $73.7 \pm 5.2$ & 0.4746 & 0.0008 & 2006 & West Virginia \\
\hline 72 & Resistant & 31 & $85.7 \pm 4.0$ & 0.0111 & $<0.0001$ & 2005 & Ohio \\
\hline 74 & Resistant & 30 & $66.4 \pm 4.1$ & 0.7860 & 0.0005 & 2005 & New York \\
\hline 75 & Resistant & 30 & $80.1 \pm 5.2$ & 0.0625 & 0.0003 & 2007 & Massachusetts \\
\hline 77 & Resistant & 31 & $82.2 \pm 8.2$ & 0.4104 & $<0.0001$ & 2005 & West Virginia \\
\hline 78 & Resistant & 30 & $97.0 \pm 8.4$ & 0.0048 & $<0.0001$ & 2005 & New York \\
\hline 80 & Resistant & 30 & $105.6 \pm 5.9$ & 0.0002 & $<0.0001$ & 2005 & New York \\
\hline 82 & Resistant & 30 & $73.9 \pm 3.6$ & 0.1363 & $<0.0001$ & 2005 & Ohio \\
\hline 83 & Resistant & 30 & $63.0 \pm 4.7$ & 0.4261 & 0.0050 & 2007 & New York \\
\hline 84 & Resistant & 31 & $67.6 \pm 6.7$ & 0.3556 & 0.0050 & 2008 & Rhode Island \\
\hline 87 & Resistant & 30 & $68.7 \pm 5.0$ & 0.6056 & $<0.0001$ & 2005 & Ohio \\
\hline 88 & Resistant & 37 & $87.8 \pm 4.7$ & 0.0008 & $<0.0001$ & 2013 & New York \\
\hline 90 & Resistant & 34 & $80.7 \pm 4.8$ & 0.0295 & $<0.0001$ & 2009 & Pennsylvania \\
\hline 94 & Resistant & 26 & $83.8 \pm 13.3$ & 0.8396 & 0.0015 & 2006 & Massachusetts \\
\hline 96 & Resistant & 30 & $82.9 \pm 4.8$ & 0.0244 & $<0.0001$ & 2005 & West Virginia \\
\hline 97 & Resistant & 30 & $90.7 \pm 3.7$ & 0.0020 & $<0.0001$ & 2007 & Rhode Island \\
\hline 98 & Resistant & 25 & $84.6 \pm 8.5$ & 0.1736 & 0.0001 & 2008 & New York \\
\hline 99 & Resistant & 35 & $94.2 \pm 7.6$ & 0.0105 & $<0.0001$ & 2008 & New York \\
\hline & & & & & & \multicolumn{2}{|c|}{ (continued on next page) } \\
\hline
\end{tabular}

a Orchard designations in bold designate the resistant standard population and the sensitive standard population used for determining the myclobutanil sensitivity classification according to the Kolmogorov-Smirnov (K-S) two-sample test. Both the resistant and sensitive standard are designated in bold text.

${ }^{\mathrm{b}}$ Orchard classification was determined by comparing the distribution of myclobutanil sensitivity responses (isolate percent mean relative growth [\%RG] values) for a given $V$. inaequalis orchard population with standard orchard populations with and without practical resistance to myclobutanil using the K-S two-sample test in SAS (version 9.3; SAS Institute, Cary, NC). Red-sens. = reduced sensitive.

${ }^{\mathrm{c}}$ Orchard population mean percent growth of $V$. inaequalis isolates on medium amended with analytical-grade myclobutanil at $0.1 \mu \mathrm{g} \mathrm{ml}{ }^{-1}$ relative to that on nonfungicide medium (\%RG). Values are means and standard errors of $n$ isolates for each population, with five single-conidium colonies for each isolate.

${ }^{\mathrm{d}}$ Probability that the distribution of sensitivity responses for the orchard population in question is not significantly different from the standard orchard population with $(\mathrm{Pr}>$ Ksa resistant) or without $(\mathrm{Pr}>$ Ksa sensitive) practical resistance to myclobutanil. 
Table 1. (continued from preceding page)

\begin{tabular}{|c|c|c|c|c|c|c|c|}
\hline Orchard $^{a}$ & Classification $^{\mathbf{b}}$ & $n$ & $\% \mathbf{R G}^{\mathbf{c}}$ & Pr $>$ Ksa resistant ${ }^{d}$ & Pr $>$ Ksa sensitived & Year & State \\
\hline 100 & Resistant & 30 & $61.8 \pm 4.4$ & 0.0877 & 0.0010 & 2006 & New York \\
\hline 102 & Resistant & 34 & $61.6 \pm 5.0$ & 0.9072 & 0.0097 & 2008 & Massachusetts \\
\hline 103 & Resistant & 27 & $82.0 \pm 11.1$ & 0.0273 & $<0.0001$ & 2008 & Rhode Island \\
\hline 105 & Resistant & 32 & $114.8 \pm 13.8$ & $<0.0001$ & $<0.0001$ & 2005 & Ohio \\
\hline 106 & Resistant & 30 & $65.9 \pm 7.6$ & 0.2317 & 0.0092 & 2007 & New York \\
\hline 107 & Resistant & 33 & $69.1 \pm 6.1$ & 0.0885 & 0.0004 & 2009 & New York \\
\hline 108 & Resistant & 41 & $53.1 \pm 5.6$ & 0.5169 & 0.0347 & 2009 & Michigan \\
\hline 109 & Resistant & 30 & $73.6 \pm 7.4$ & 0.2973 & 0.0050 & 2007 & New York \\
\hline 111 & Resistant & 30 & $79.4 \pm 11.3$ & 0.4754 & $<0.0001$ & 2007 & Rhode Island \\
\hline 113 & Resistant & 30 & $93.9 \pm 8.1$ & 0.1050 & $<0.0001$ & 2007 & New York \\
\hline 117 & Resistant & 30 & $78.7 \pm 5.5$ & 0.1387 & $<0.0001$ & 2004 & New York \\
\hline 118 & Resistant & 29 & $60.0 \pm 4.5$ & 0.3550 & 0.0040 & 2007 & New York \\
\hline 120 & Resistant & 30 & $84.0 \pm 6.9$ & 0.0625 & $<0.0001$ & 2005 & West Virginia \\
\hline 121 & Resistant & 29 & $80.3 \pm 7.9$ & 0.4495 & $<0.0001$ & 2006 & Rhode Island \\
\hline 122 & Resistant & 30 & $64.4 \pm 4.4$ & 0.6984 & 0.0008 & 2005 & New York \\
\hline 124 & Resistant & 30 & $116.4 \pm 11.1$ & $<0.0001$ & $<0.0001$ & 2006 & Massachusetts \\
\hline 125 & Resistant & 30 & $132.4 \pm 12.7$ & $<0.0001$ & $<0.0001$ & 2005 & New York \\
\hline 127 & Resistant & 30 & $94.4 \pm 4.3$ & 0.0004 & $<0.0001$ & 2005 & Wisconsin \\
\hline 141 & Resistant & 21 & $73.4 \pm 7.3$ & 0.8552 & 0.0002 & 2010 & Maine \\
\hline 148 & Resistant & 21 & $77.9 \pm 2.3$ & 0.0008 & $<0.0001$ & 2011 & New York \\
\hline 149 & Resistant & 21 & $94.9 \pm 3.0$ & $<0.0001$ & 0.0004 & 2009 & Massachusetts \\
\hline 150 & Resistant & 18 & $93.4 \pm 5.6$ & 0.0115 & $<0.0001$ & 2011 & Virginia \\
\hline 154 & Resistant & 16 & $98.4 \pm 5.2$ & 0.0033 & $<0.0001$ & 2011 & North Carolina \\
\hline 157 & Resistant & 31 & $82.0 \pm 3.5$ & 0.8639 & $<0.0001$ & 2012 & Vermont \\
\hline 158 & Resistant & 24 & $68.8 \pm 4.5$ & 0.2249 & 0.0015 & 2011 & Maine \\
\hline 162 & Resistant & 24 & $60.3 \pm 4.2$ & 0.1778 & 0.0096 & 2012 & Michigan \\
\hline 163 & Resistant & 36 & $78.0 \pm 3.5$ & 0.7264 & $<0.0001$ & 2012 & Maine \\
\hline 170 & Resistant & 33 & $76.3 \pm 3.9$ & 0.7767 & $<0.0001$ & 2012 & New York \\
\hline 172 & Resistant & 35 & $70.0 \pm 2.6$ & 0.7497 & $<0.0001$ & 2012 & New York \\
\hline 173 & Resistant & 17 & $87.2 \pm 8.1$ & 0.0448 & 0.0020 & 2013 & Vermont \\
\hline 175 & Resistant & 26 & $99.2 \pm 3.6$ & $<0.0001$ & $<0.0001$ & 2013 & New York \\
\hline 30 & Red-sens. & 24 & $55.8 \pm 7.9$ & 0.2423 & 0.3291 & 2007 & Massachusetts \\
\hline 33 & Red-sens. & 30 & $50.2 \pm 4.0$ & 0.0055 & 0.0215 & 2007 & New Hampshire \\
\hline 44 & Red-sens. & 30 & $60.6 \pm 13.8$ & 0.4261 & 0.0751 & 2007 & Rhode Island \\
\hline 51 & Red-sens. & 30 & $57.5 \pm 4.2$ & 0.0429 & 0.0007 & 2006 & New York \\
\hline 62 & Red-sens. & 30 & $59.5 \pm 6.7$ & 0.0877 & 0.0751 & 2006 & New York \\
\hline 76 & Red-sens. & 30 & $54.3 \pm 5.0$ & 0.0484 & 0.0076 & 2006 & Vermont \\
\hline 89 & Red-sens. & 30 & $49.2 \pm 2.8$ & 0.0063 & 0.0119 & 2005 & New Hampshire \\
\hline 104 & Red-sens. & 24 & $48.0 \pm 2.5$ & $<0.0001$ & 0.0068 & 2011 & Maine \\
\hline 110 & Red-sens. & 34 & $55.3 \pm 3.2$ & 0.0001 & 0.0053 & 2012 & Vermont \\
\hline 142 & Red-sens. & 35 & $48.3 \pm 1.8$ & $<0.0001$ & 0.0183 & 2013 & Michigan \\
\hline 147 & Red-sens. & 23 & $62.3 \pm 3.8$ & 0.0158 & 0.0004 & 2012 & New York \\
\hline 153 & Red-sens. & 20 & $52.5 \pm 3.4$ & $<0.0001$ & 0.0068 & 2011 & Maine \\
\hline 164 & Red-sens. & 37 & $58.9 \pm 3.4$ & 0.0006 & 0.0027 & 2012 & New York \\
\hline 165 & Red-sens. & 19 & $62.6 \pm 3.4$ & 0.0117 & 0.0014 & 2012 & Massachusetts \\
\hline 171 & Red-sens. & 34 & $68.8 \pm 3.3$ & 0.024 & $<0.0001$ & 2012 & New York \\
\hline 174 & Red-sens. & 37 & $49.5 \pm 3.3$ & 0.0046 & 0.0158 & 2013 & Maine \\
\hline 4 & Sensitive & 30 & $50.0 \pm 6.7$ & 0.0025 & 0.1600 & 2007 & New Hampshire \\
\hline 11 & Sensitive & 30 & $50.8 \pm 4.4$ & 0.0356 & 0.0842 & 2007 & Rhode Island \\
\hline 13 & Sensitive & 26 & $41.2 \pm 13.8$ & $<0.0001$ & 0.2924 & 2011 & New York \\
\hline 23 & Sensitive & 30 & $27.8 \pm 2.1$ & $<0.0001$ & 0.0842 & 2007 & New York \\
\hline 28 & Sensitive & 17 & $12.9 \pm 3.4$ & $<0.0001$ & 0.0088 & 2010 & New York \\
\hline 29 & Sensitive & 36 & $30.9 \pm 2.1$ & $<0.0001$ & 0.1243 & 2008 & Rhode Island \\
\hline 32 & Sensitive & 17 & $23.5 \pm 7.5$ & 0.0004 & 0.0494 & 2009 & Michigan \\
\hline 41 & Sensitive & 30 & $37.5 \pm 4.9$ & $<0.0001$ & 0.4260 & 2007 & Rhode Island \\
\hline 46 & Sensitive & 22 & $13.7 \pm 5.2$ & $<0.0001$ & 0.0004 & 2009 & Michigan \\
\hline 50 & Sensitive & 33 & $36.4 \pm 6.7$ & 0.0023 & 0.1945 & 2009 & New York \\
\hline 52 & Sensitive & 15 & $29.4 \pm 6.9$ & 0.0183 & 0.9048 & 2009 & Ohio \\
\hline 58 & Sensitive & 20 & $29.3 \pm 6.5$ & 0.0017 & 0.3446 & 2009 & Michigan \\
\hline 61 & Sensitive & 36 & $38.4 \pm 3.6$ & 0.0007 & 1.0000 & 2011 & New York \\
\hline 69 & Sensitive & 19 & $21.9 \pm 6.2$ & 0.0009 & 0.1575 & 2005 & New York \\
\hline 71 & Sensitive & 16 & $33.6 \pm 2.9$ & 0.0002 & 0.4930 & 2004 & New York \\
\hline
\end{tabular}


Table 1. (continued from preceding page)

\begin{tabular}{|c|c|c|c|c|c|c|c|}
\hline Orcharda $^{a}$ & Classification $^{b}$ & $n$ & $\% \mathbf{R G}^{\mathbf{c}}$ & Pr $>$ Ksa resistant ${ }^{d}$ & Pr $>$ Ksa sensitive ${ }^{d}$ & Year & State \\
\hline 86 & Sensitive & 17 & $33.0 \pm 6.6$ & 0.0054 & 0.4576 & 2013 & Maine \\
\hline 92 & Sensitive & 34 & $9.0 \pm 2.1$ & $<0.0001$ & 0.0002 & 2009 & Indiana \\
\hline 93 & Sensitive & 20 & $25.7 \pm 9.3$ & $<0.0001$ & 0.0096 & 2009 & Maine \\
\hline 101 & Sensitive & 22 & $30.0 \pm 3.5$ & $<0.0001$ & 0.5401 & 2012 & New York \\
\hline 112 & Sensitive & 30 & $54.7 \pm 4.5$ & 0.0066 & 0.1445 & 2006 & New York \\
\hline 115 & Sensitive & 24 & $40.5 \pm 5.5$ & 0.0026 & 0.8186 & 2005 & Massachusetts \\
\hline 116 & Sensitive & 33 & $46.2 \pm 6.4$ & 0.0109 & 0.7252 & 2009 & New York \\
\hline 119 & Sensitive & 19 & $46.9 \pm 12.2$ & 0.0063 & 0.4413 & 2010 & West Virginia \\
\hline 128 & Sensitive & 33 & $37.9 \pm 2.8$ & 0.0001 & 0.2321 & 2004 & New York \\
\hline 151 & Sensitive & 24 & $42.6 \pm 3.6$ & $<0.0001$ & 0.1725 & 2011 & Maine \\
\hline 152 & Sensitive & 26 & $43.7 \pm 3.1$ & $<0.0001$ & 0.0613 & 2011 & Maine \\
\hline 155 & Sensitive & 15 & $51.1 \pm 4.4$ & 0.0002 & 0.0506 & 2011 & Maine \\
\hline 161 & Sensitive & 15 & $47.4 \pm 9.3$ & 0.0015 & 0.5137 & 2010 & New York \\
\hline 166 & Sensitive & 31 & $16.1 \pm 1.7$ & $<0.0001$ & 0.0002 & 2012 & Maine \\
\hline 167 & Sensitive & 33 & $36.7 \pm 2.1$ & $<0.0001$ & 0.1618 & 2012 & Maine \\
\hline 168 & Sensitive & 25 & $30.6 \pm 4.9$ & $<0.0001$ & 0.5061 & 2012 & Maine \\
\hline 169 & Sensitive & 24 & $51.6 \pm 5.0$ & 0.001 & 0.0621 & 2012 & Maryland \\
\hline
\end{tabular}

Baseline sensitivity and sensitivity of populations of $\mathrm{V}$. inaequalis to difenoconazole. In order to develop a baseline for difenoconazole sensitivity in $\mathrm{V}$. inaequalis, $44 \mathrm{~V}$. inaequalis single conidial lesion isolates were collected from two baseline apple orchards located in Geneva, NY, in 2010 and were screened for sensitivity to difenoconazole. For each single conidial lesion isolate, conidial suspensions were prepared as described above and were evenly distributed on PDA medium that was amended with streptomycin sulfate (50 $\mu \mathrm{g} \mathrm{ml}^{-1}$ ), chloramphenicol $\left(50 \mu \mathrm{g} \mathrm{ml}^{-1}\right)$, and analytical grade difenoconazole (Sigma Aldrich) at final concentrations of 0.0 , $0.0001,00005,0.001,0.01,0.05,0.1,0.5$, and $1 \mu \mathrm{g} \mathrm{ml}^{-1}$. Following 6 days of incubation at $22^{\circ} \mathrm{C}$, mycelial growth of five randomly selected microcolonies originating from single spores was determined by measuring microcolony diameter or germ tube length (for spores with greatly inhibited growth) using a SPOT Idea digital camera attached to an Olympus SZX12 stereoscope, as described above. Relative percent inhibition was calculated at each fungicide concentration as previously described (Yoshimura et al. 2004). For each isolate, dose response curves were constructed using relative percent inhibition of colony growth at each log-transformed $\left(\log _{10}\right)$ concentration for the respective fungicide to determine the value of the effective concentration that inhibited isolate growth by $50 \%\left(\mathrm{EC}_{50}\right)$.

From 2010 to 2013, single conidial lesion isolates that were used for the determination of myclobutanil sensitivity were also screened for sensitivity to analytical grade difenoconazole at a discriminatory concentration of $0.1 \mu \mathrm{g} \mathrm{ml}^{-1}$. This concentration was chosen on the basis of being able to make comparisons of intrinsic activity with myclobutanil. Difenoconazole sensitivity, expressed as \%RG, was determined in an identical manner as the myclobutanil sensitivity assay described above. Orchards were classified as sensitive, reduced sensitive, or resistant using the K-S two-sample test, as described above. Because control failures with difenoconazole have not been reported in the region, we expected that the sensitivity responses of $V$. inaequalis isolates to difenoconazole in vitro would have to approach the same level of growth response that allows an isolate or population to achieve resistance to myclobutanil in order for practical resistance to be observed. Thus, the DMI-sensitive and -resistant orchards used for the classification of myclobutanil sensitivity were used to classify orchard sensitivity to difenoconazole using the same sensitive and resistant thresholds.

Myclobutanil and difenoconazole cross-sensitivity in a representative baseline (orchard 28) and a myclobutanil-resistant population of $V$. inaequalis (orchard 37) was also evaluated in 2013. In all, 17 isolates from a baseline orchard and 35 isolates from a myclobutanilresistant orchard were assayed for sensitivity to both fungicides. Simple linear regression analysis was used to determine whether there was a relationship between RG responses between the two fungicides in vitro (SigmaPlot version 11.0; Systat Software Inc.).
Impact of DMI fungicide applications on myclobutanil and difenoconazole sensitivity. From 2010 to 2013 , sensitivity to myclobutanil and difenoconazole was evaluated in a research orchard composed of 15-year-old 'Empire' apple on M.9/M.111 rootstocks. Prior to 2010 , myclobutanil had provided acceptable levels of control (i.e., <20\% incidence) on mature fruit (Cox et al. 2009), and trees within this research orchard had only received a total of 12 applications of myclobutanil during its production history. To determine the effect of difenoconazole applications on $V$. inaequalis populations sensitive to DMI fungicides, four applications of Inspire (difenoconazole; Syngenta) were made each year from 2010 to 2013 at the maximum labeled rate of $293 \mathrm{ml} \mathrm{ha}^{-1}$. Inspire was applied in approximately 2,800 liters of water per hectare using an AA2 GunJet handgun (TeeJet Technologies) at approximately 2,000 kPA pressure. Treatments were applied on approximately 7- to 10-day intervals at the phenological timings of pink, bloom, first cover, and second cover. Isolated primary apple scab lesions were collected in the spring of 2010 to 2013 and were assayed for sensitivity to myclobutanil and difenoconazole, as described above.

To determine the impact of DMI fungicide applications and the degree of stability of myclobutanil resistance, changes in myclobutanil sensitivity were evaluated in a 30-year-old McIntosh and 'Cortland' research apple orchard with a $V$. inaequalis population previously confirmed to have practical resistance to myclobutanil (Turechek et al. 2005). From 2005 to 2010, Nova 40W or Rally 40WSP was applied at a rate of $333 \mathrm{~g} \mathrm{ha}^{-1}$. Rally 40WSP was applied at the same phenological timings using the same application parameters as described above for the Empire planting. From 2011 to 2013, the myclobutanil selective pressure was removed from the orchard and DMI fungicides were no longer applied during the remainder of the study. In each year, isolated primary apple scab lesions were collected in the spring of 2005 to 2013 and were assayed for sensitivity to myclobutanil as described above.

\section{Results}

Myclobutanil sensitivity of $\boldsymbol{V}$. inaequalis orchard populations. From 2004 to 2013, 141 individual populations of $V$. inaequalis throughout the northeastern United States were evaluated for sensitivity to myclobutanil (Table 1). In total, 3,987 single-conidial lesion isolates of $V$. inaequalis were tested for sensitivity to myclobutanil, with 107 of the orchard populations being represented by 25 or more isolates. The remaining 34 orchard populations were represented by a minimum of 15 isolates.

Throughout the 10-year study, 89 of the 141 (63\%) orchard populations of $V$. inaequalis were determined to have practical resistance to myclobutanil on the basis of statistical comparisons with sensitive and resistant population standards. The mean \% RG of the orchards with practical resistance ranged from 53.1 to $132.4 \%$, with a research 
orchard population from East Lansing, MI (orchard 108: $53.1 \pm$ $5.6 \%$ ) and a commercial orchard population from Chazy, NY (orchard 125: $132.4 \pm 12.7 \%$ ) having the lowest and highest RG, respectively. Seventy-nine of the orchard populations exhibiting practical resistance to myclobutanil were commercial orchards. Within these commercial orchards, myclobutanil (Nova 40W or Rally 40WSP) was applied for an average of 13 years with two to four applications of the fungicide per season. The remaining orchard populations classified as having practical resistance to myclobutanil were from research orchards in which DMI fungicides had been applied regularly throughout the planting history.

Only 18 (13\%) orchard populations of $V$. inaequalis were found to have reduced sensitivity to myclobutanil. The mean $\%$ RG for these populations ranged from 48.0 to $68.8 \%$ with an orchard from Wells, ME (orchard 104: $48.0 \pm 2.5 \%$ ) and an orchard from Sodus, NY (orchard 171: $68.8 \pm 3.3$ ) representing the minimum and maximum endpoints of the reduced-sensitive designation. Sixteen orchard populations with reduced sensitivity were from commercial orchards and, in these orchards, applications of myclobutanil were made for an average of 11 years with two to four applications per season. One research orchard (orchard 62) in which DMI fungicides had been applied regularly throughout the history of the orchard and one baseline orchard (orchard 51) that had reportedly never directly been exposed to fungicides were determined to have reduced sensitivity to myclobutanil.

Table 2. Summary of Venturia inaequalis orchard populations by region and state classified on the basis of in vitro sensitivity to the demethylation inhibitor fungicides myclobutanil and difenoconazole

\begin{tabular}{|c|c|c|c|c|}
\hline \multirow{3}{*}{$\begin{array}{l}\text { Classification, } \\
\text { region, state }\end{array}$} & \multicolumn{4}{|c|}{ Orchard populations } \\
\hline & \multicolumn{2}{|c|}{ Myclobutanil } & \multicolumn{2}{|c|}{ Difenoconazole } \\
\hline & $n$ & For state $(\%)$ & $n$ & For state $(\%)$ \\
\hline \multicolumn{5}{|l|}{ Resistant } \\
\hline \multicolumn{5}{|l|}{ New England } \\
\hline Connecticut & 1 & 100 & $\ldots$ & $\ldots$ \\
\hline Massachusetts & 12 & 75 & 0 & 0 \\
\hline Maine & 6 & 35 & 0 & 0 \\
\hline New Hampshire & 1 & 25 & $\ldots$ & $\ldots$ \\
\hline Rhode Island & 9 & 64 & $\ldots$ & $\ldots$ \\
\hline Vermont & 3 & 60 & 0 & 0 \\
\hline \multicolumn{5}{|l|}{ Mid-Atlantic } \\
\hline Maryland & 0 & 0 & 0 & 0 \\
\hline North Carolina & 1 & 100 & $\ldots$ & $\ldots$ \\
\hline New York & 40 & 70 & 0 & 0 \\
\hline Pennsylvania & 1 & 100 & $\ldots$ & $\ldots$ \\
\hline Virginia & 1 & 100 & 0 & 0 \\
\hline West Virginia & 6 & 75 & 0 & 0 \\
\hline \multicolumn{5}{|l|}{ Midwest } \\
\hline Indiana & 0 & 0 & $\ldots$ & $\ldots$ \\
\hline Ohio & 5 & 83 & $\ldots$ & $\ldots$ \\
\hline Michigan & 2 & 29 & 0 & 0 \\
\hline Wisconsin & 1 & 100 & $\ldots$ & $\ldots$ \\
\hline Total & 89 & 63 & 0 & 0 \\
\hline \multicolumn{5}{|l|}{ Reduced sensitive } \\
\hline \multicolumn{5}{|l|}{ New England } \\
\hline Connecticut & 0 & 0 & $\ldots$ & $\ldots$ \\
\hline Massachusetts & 3 & 19 & 0 & 0 \\
\hline Maine & 3 & 18 & 0 & 0 \\
\hline New Hampshire & 2 & 50 & $\ldots$ & $\ldots$ \\
\hline Rhode Island & 1 & 7 & $\ldots$ & $\ldots$ \\
\hline Vermont & 2 & 40 & 0 & 0 \\
\hline
\end{tabular}

a Orchard practical resistance classification was determined by comparing the distribution of myclobutanil or difenoconazole sensitivity responses (isolate percent mean relative growth values) for a given $V$. inaequalis orchard population with standard orchard populations with and without practical resistance to myclobutanil using the Kolmogorov-Smirnov twosample test in SAS (version 9.3; SAS Institute, Cary, NC).
Thirty-four orchard populations of $V$. inaequalis (24\%) were found to be sensitive to myclobutanil. The mean $\% \mathrm{RG}$ of sensitive populations was 9.0 to $54.7 \%$, with a baseline population in West Lafayette, IN (orchard 9: $9.0 \pm 2.1$ ) and a commercial orchard surveyed in 2006 from Milton, $\mathrm{NY}$ (orchard 112: $54.7 \pm 4.5$ ) representing the minimum and maximum mean $\% \mathrm{RG}$, respectively, in this classification. Of the 34 sensitive orchard populations, 24 were commercial orchards where myclobutanil was applied for an average of 9 years, with approximately one to two applications per season. Three populations from research orchards that had received applications of DMI fungicides throughout the history of their planting and seven of the eight total baseline orchard populations were found to be sensitive to myclobutanil.

For the purpose of examining broader implications of myclobutanil resistance, orchard populations were sorted by their myclobutanil sensitivity classification according to the state and region from which they were collected (Table 2). Overall, 57, 69, and 15 populations of $V$. inaequalis were examined from the New England region (Connecticut, Maryland, Maine, New Hampshire, Rhode Island, and Vermont), the mid-Atlantic region (North Carolina, New York, Pennsylvania, Virginia, and West Virginia), and the Midwest region (Indiana, Michigan, Ohio, and Wisconsin), respectively. Although the majority of populations from each region were resistant to myclobutanil, the mid-Atlantic had the highest percentage of resistant populations $(71 \%)$ followed by New England (56\%) and the Midwest (53\%). The Midwest had the greatest percentage of populations that were sensitive to myclobutanil (33\%). Of the states (Maryland, Maine, New York, and Rhode Island) in which more than 10

Table 2. (continued from preceding column)

\begin{tabular}{|c|c|c|c|c|}
\hline \multirow{3}{*}{$\begin{array}{l}\text { Classification, } \\
\text { region, state }^{\mathrm{a}}\end{array}$} & \multicolumn{4}{|c|}{ Orchard populations } \\
\hline & \multicolumn{2}{|c|}{ Myclobutanil } & \multicolumn{2}{|c|}{ Difenoconazole } \\
\hline & $n$ & For state $(\%)$ & $n$ & For state $(\%)$ \\
\hline \multicolumn{5}{|l|}{ Mid-Atlantic } \\
\hline Maryland & 0 & 0 & 0 & 0 \\
\hline North Carolina & 0 & 0 & $\ldots$ & $\ldots$ \\
\hline New York & 5 & 9 & 1 & 7 \\
\hline Pennsylvania & 0 & 0 & $\ldots$ & $\ldots$ \\
\hline Virginia & 0 & 0 & 0 & 0 \\
\hline West Virginia & 0 & 0 & 0 & 0 \\
\hline \multicolumn{5}{|l|}{ Midwest } \\
\hline Indiana & 0 & 0 & $\ldots$ & $\ldots$ \\
\hline Michigan & 2 & 29 & 0 & 0 \\
\hline Ohio & 0 & 0 & $\ldots$ & $\ldots$ \\
\hline Wisconsin & 0 & 0 & $\ldots$ & $\ldots$ \\
\hline Total & 18 & 13 & 1 & 3 \\
\hline \multicolumn{5}{|l|}{ Sensitive } \\
\hline \multicolumn{5}{|l|}{ New England } \\
\hline Connecticut & 0 & 0 & $\ldots$ & $\ldots$ \\
\hline Massachusetts & 1 & 6 & 1 & 100 \\
\hline Maine & 9 & 45 & 13 & 100 \\
\hline New Hampshire & 1 & 25 & $\ldots$ & $\ldots$ \\
\hline Rhode Island & 4 & 29 & $\ldots$ & $\ldots$ \\
\hline Vermont & 0 & 0 & 4 & 100 \\
\hline \multicolumn{5}{|l|}{ Mid-Atlantic } \\
\hline Maryland & 1 & 100 & 1 & 100 \\
\hline North Carolina & 0 & 0 & $\ldots$ & $\ldots$ \\
\hline New York & 12 & 21 & 13 & 93 \\
\hline Pennsylvania & 0 & 0 & $\ldots$ & $\ldots$ \\
\hline Virginia & 0 & 0 & 1 & 100 \\
\hline West Virginia & 2 & 25 & 1 & 100 \\
\hline \multicolumn{5}{|l|}{ Midwest } \\
\hline Indiana & 1 & 100 & $\ldots$ & $\ldots$ \\
\hline Michigan & 3 & 43 & 2 & 100 \\
\hline Ohio & 1 & 16 & $\ldots$ & $\ldots$ \\
\hline Wisconsin & 0 & 0 & $\ldots$ & $\ldots$ \\
\hline Total & 34 & 24 & 36 & 97 \\
\hline
\end{tabular}


populations of $V$. inaequalis were investigated, only Maine had more populations that were sensitive to myclobutanil $(45 \%)$ than were resistant to myclobutanil (35\%).

Baseline sensitivity and sensitivity of populations of $V$. inaequalis to difenoconazole. The $\mathrm{EC}_{50}$ values for baseline isolates of $V$. inaequalis to difenoconazole were 0.0002 to $0.009 \mu \mathrm{g} \mathrm{ml}^{-1}$ (mean $\mathrm{EC}_{50}=0.002 \mu \mathrm{g} \mathrm{ml}^{-1}$ ) (Fig. 1). The majority (39 of 44) of isolates screened for baseline sensitivity had $\mathrm{EC}_{50}$ values below $0.004 \mu \mathrm{g} \mathrm{ml}^{-1}$. Although a few isolates demonstrated a slight reduction in sensitivity to difenoconazole, no isolates tested had $\mathrm{EC}_{50}$ values that were either less than or greater than $10 \times$ the mean $\left(0.002 \mu \mathrm{g} \mathrm{ml}^{-1}\right)$.

From 2010 to 2013, 37 orchard populations of $V$. inaequalis throughout the northeastern United States were evaluated for sensitivity to difenoconazole (Table 3 ). Of these populations, 3 were from baseline orchards, 6 were from research orchards, and 28 were from commercial orchards. In total, 1,012 single-conidial lesion isolates of $V$. inaequalis were tested for sensitivity to difenoconazole, with 20 of the orchard populations being represented by 25 or more isolates. The remaining 17 orchard populations were represented by a minimum of 15 isolates.

None of the orchard populations was found to have practical resistance to difenoconazole, and only one population (orchard 148) was found to have reduced sensitivity to difenoconazole. The population with reduced sensitivity to difenoconazole was collected from a commercial orchard in which DMI fungicides had been used extensively and had a history of practical resistance to myclobutanil. This reduced-sensitive population had a mean $\%$ RG on difenoconazoleamended medium of $42.0 \pm 6.1 \%$. Thirty-six remaining orchard populations were classified as being sensitive to difenoconazole. The mean \% RG of sensitive orchard populations ranged from 3.2 to $41.1 \%$, with a commercial orchard population in Sweden, ME (orchard 86: $3.2 \pm 1.2 \%$ ) and a commercial orchard population in Geneva, NY (orchard 164: $41.1 \pm 2.9 \%$ ) having the lowest and highest RG, respectively. Within all 29 commercial orchard populations, myclobutanil (Nova 40W or Rally 40WSP) was applied for an average of 13 years with two to four applications per season. Because difenoconazole in the form of Inspire Super (difenoconazole + cyprodinil; Syngenta) was first registered for use in New York in 2009, the product had only been available for use a maximum of four seasons, and most growers had only made one to two applications per season during those four seasons.

With the exception of a baseline orchard (orchard 28), all orchard populations were more sensitive to difenoconazole compared with myclobutanil and most individual isolates were more sensitive to difenoconazole than myclobutanil (data not shown). Of the 37 orchard populations surveyed for sensitivity to both fungicides, four

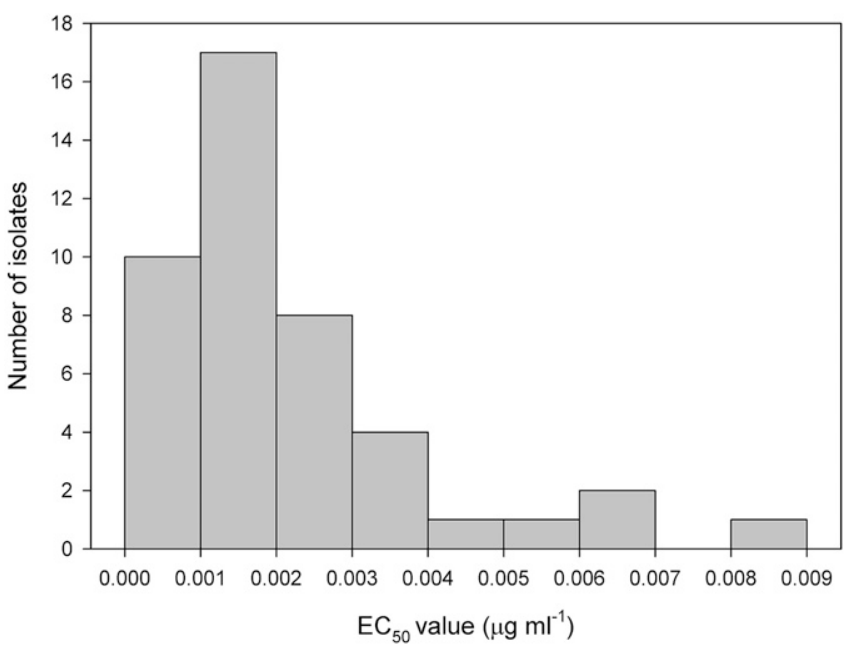

Fig. 1. Distribution of difenoconazole $\mathrm{EC}_{50}$ values for 44 baseline isolates of Venturia inaequalis. Baseline isolates were collected from apple orchards in New York that have never been exposed to single-site fungicides. distinct phenotypic combinations were observed. In all, 14 orchard populations were found to be resistant to myclobutanil but sensitive to difenoconazole, 10 orchard populations had reduced sensitivity to myclobutanil but were sensitive to difenoconazole, 1 orchard population was resistant to myclobutanil and had reduced sensitivity to difenoconazole, and 12 orchard populations were sensitive to both fungicides (Tables 1 and 3). In a representative baseline population (orchard 28), some cross-sensitivity was observed between difenoconazole and myclobutanil $(R=0.61)$ (Fig. 2A). However, there was little to no cross-sensitivity between the two fungicides in a representative population with myclobutanil resistance (orchard 37) $(R=$ 0.07) (Fig. 2B).

Impact of difenoconazole or myclobutanil fungicide applications on DMI fungicide sensitivity. In the Empire orchard, Inspire (difenoconazole) was applied a total of 16 times from 2010 to 2013. A decrease in sensitivity ("increase in resistance") to both myclobutanil and difenoconazole was observed in the population of $V$. inaequalis that was exposed to Inspire during this 4-year period (Fig. 3). Losses in sensitivity to myclobutanil increased steadily at a rate of $25 \% \mathrm{RG}$ per year (Fig. 3). In 2010, the mean \%RG of this population on medium amended with myclobutanil was $23.8 \pm$ $6.8 \%$. By 2013, the population had developed practical resistance to myclobutanil, with a mean $\% \mathrm{RG}$ of $96.4 \pm 2.2 \%$. Although a loss of sensitivity to difenoconazole was also observed, percent changes in sensitivity during the 4-year period were not nearly as high as those for myclobutanil. In 2010, the isolate mean \%RG on difenoconazole-amended medium was $19.0 \pm 8.9 \%$ and, by 2013 , the population was still sensitive to the fungicide, with an isolate mean \%RG of $39.1 \pm 4.5 \%$ (Fig. 3 ).

In vitro sensitivity to myclobutanil and difenoconazole was also determined for an orchard population with previously confirmed practical resistance to myclobutanil (Turechek et al. 2005). In the McIntosh and Cortland orchard from 2005 to 2010, myclobutanil (Rally 40WSP or Nova 40W) was applied 24 times. Interestingly, no significant difference in myclobutanil sensitivity was observed between the population evaluated in $2005(82.6 \pm 8.1 \%)$ and that evaluated in $2010(88.5 \pm 5.0 \%)$ (Fig. 4). In addition, when myclobutanil applications were terminated in the orchard (2011 to 2013), no significant difference in sensitivity to myclobutanil was observed compared with the years in which myclobutanil was applied in the orchard (2005 to 2010). Surprisingly, sensitivity to myclobutanil actually decreased from 2011 to 2013, with isolate mean \%RG on myclobutanil-amended medium during those years increasing from $84.2 \pm 5.3$ to $93.2 \pm 2.2 \%$. In vitro sensitivity to difenoconazole was lower than that of myclobutanil, ranging from $34.7 \pm 4.1$ to $44.3 \pm 2.2 \%$ between 2009 and 2013 , with a similar lack of fluctuation between years (Fig. 4).

\section{Discussion}

In all, 141 individual orchard populations of $V$. inaequalis from 16 states representing three major geographic regions were tested for sensitivity to the DMI fungicide myclobutanil over a period of 10 years. The majority of orchard populations were found to have practical resistance to the fungicide. Many of these orchards were commercial operations with an average of 13 applications of myclobutanil throughout the history of the orchard. Although myclobutanil may no longer be a reliable apple scab management option in orchards east of the Mississippi River, the use of newly released DMI fungicides such as difenoconazole may still be an effective alternative in management of apple scab. Indeed, nearly all populations of $V$. inaequalis tested for sensitivity to difenoconazole were found to be sensitive despite their phenotypic responses on myclobutanilamended medium.

Resistance to myclobutanil and other DMI fungicides began appearing in commercial $V$. inaequalis populations as early as 1991 (Köller et al. 1997) and is now prevalent in major apple production regions, including those in Michigan, Virginia, Pennsylvania, Indiana, and Nova Scotia (Chapman et al. 2011; Köller et al. 1997; Marine et al. 2007; Pfeufer and Ngugi 2012). Although resistance to myclobutanil was previously detected in individual isolates of 
$V$. inaequalis from New York (Köller et al. 1997), this is the first report of widespread myclobutanil resistance in the state and the New England region. Overall, 89 of 141 orchard populations across 16 states were confirmed to have practical resistance to myclobutanil. Because the distribution of myclobutanil sensitivity of isolates within each population was directly compared with a standard orchard population in which myclobutanil failed to adequately control apple scab, it is possible that myclobutanil could be ineffective in these 89 orchards, dependent on the susceptibility of the cultivar and weather during subsequent growing seasons.

Although the majority of orchard populations screened for myclobutanil sensitivity in this study were collected from orchards in which myclobutanil failed to provide adequate levels of apple scab control in the field, there were a few instances in which a field failure was reported but the population tested sensitive or reduced sensitive to myclobutanil in vitro. This was especially the case in 2009, in which there was low apple scab infection pressure through bloom throughout the northeastern United States, followed by favorable secondary apple scab conditions throughout the summer months. Dry conditions through bloom resulted in longer than average application intervals and, as a result, minor primary apple scab infection events may have been missed. The weather across the region following petal fall and continuing throughout the summer months was wet and accompanied by below-average temperatures (Rosenberger et al. 2010). Usually during the summer, secondary apple scab infection slows because of a reduction of conidial production when temperatures surpass 26 to $29^{\circ} \mathrm{C}$ (MacHardy 1996). Because primary infections may have become established during the prebloom period, and because of the lack of consecutive days with warm temperatures to retard conidial production, the appearance of apple scab symptoms may have been mistaken for a fungicide control failure. Interestingly, several orchard populations evaluated for sensitivity in 2009 arrived for screening following petal fall. In other years of the survey, poor coverage or sprayer calibration may have resulted in fungicide control failures in the field rather than fungicide resistance.

Surprisingly, one baseline orchard without any historical applications of DMI fungicides was classified as reduced sensitive in this study. Although there are considerable numbers of wild apple trees in the region, the baseline orchard was fairly geographically isolated from commercial operations. Because the spatial spread of isolates of

Table 3. Sensitivity classification, percent relative growth, isolation year, and collection location from which Venturia inaequalis populations were surveyed for difenoconazole resistance

\begin{tabular}{|c|c|c|c|c|c|c|c|}
\hline Orchard $^{\mathrm{a}}$ & Classification $^{\mathbf{b}}$ & $n$ & $\% \mathrm{RG}^{\mathrm{c}}$ & Pr $>$ Ksa resistant ${ }^{d}$ & Pr $>$ Ksa sensitive ${ }^{d}$ & Year & State \\
\hline 148 & Red-sens. & 21 & $42.0 \pm 6.1$ & 0.0750 & 0.8135 & 2011 & New York \\
\hline 13 & Sensitive & 25 & $11.3 \pm 1.5$ & $<0.0001$ & $<0.0001$ & 2011 & New York \\
\hline 19 & Sensitive & 26 & $24.8 \pm 3.0$ & $<0.0001$ & 0.0863 & 2013 & Vermont \\
\hline 26 & Sensitive & 35 & $35.0 \pm 3.5$ & $<0.0001$ & 0.5187 & 2010 & New York \\
\hline 28 & Sensitive & 17 & $16.0 \pm 2.7$ & $<0.0001$ & 0.0006 & 2011 & New York \\
\hline 37 & Sensitive & 35 & $39.1 \pm 4.5$ & 0.0011 & 0.2714 & 2013 & New York \\
\hline 43 & Sensitive & 31 & $13.1 \pm 2.1$ & $<0.0001$ & 0.0005 & 2012 & Maine \\
\hline 61 & Sensitive & 36 & $21.9 \pm 3.5$ & $<0.0001$ & 0.1131 & 2011 & New York \\
\hline 86 & Sensitive & 16 & $3.2 \pm 1.2$ & $<0.0001$ & $<0.0001$ & 2013 & Maine \\
\hline 88 & Sensitive & 35 & $22.3 \pm 3.3$ & $<0.0001$ & 0.0023 & 2013 & New York \\
\hline 101 & Sensitive & 22 & $15.1 \pm 3.1$ & $<0.0001$ & 0.0071 & 2012 & New York \\
\hline 104 & Sensitive & 23 & $5.7 \pm 0.6$ & $<0.0001$ & $<0.0001$ & 2011 & Maine \\
\hline 110 & Sensitive & 34 & $29.7 \pm 3.1$ & $<0.0001$ & 0.3625 & 2012 & Vermont \\
\hline 119 & Sensitive & 19 & $11.1 \pm 4.6$ & $<0.0001$ & 0.0003 & 2010 & West Virginia \\
\hline 141 & Sensitive & 21 & $23.6 \pm 6.1$ & 0.0010 & 0.0911 & 2010 & Maine \\
\hline 142 & Sensitive & 36 & $12.6 \pm 1.8$ & $<0.0001$ & $<0.0001$ & 2013 & Michigan \\
\hline 147 & Sensitive & 23 & $37.6 \pm 3.9$ & 0.0013 & 0.8305 & 2012 & New York \\
\hline 150 & Sensitive & 17 & $12.6 \pm 2.7$ & $<0.0001$ & 0.0009 & 2011 & Virginia \\
\hline 151 & Sensitive & 23 & $12.6 \pm 2.4$ & $<0.0001$ & 0.0001 & 2011 & Maine \\
\hline 152 & Sensitive & 25 & $24.8 \pm 4.3$ & $<0.0001$ & 0.1736 & 2011 & Maine \\
\hline 153 & Sensitive & 19 & $16.3 \pm 3.5$ & $<0.0001$ & 0.0016 & 2011 & Maine \\
\hline 157 & Sensitive & 32 & $27.3 \pm 3.2$ & $<0.0001$ & 0.1464 & 2012 & Vermont \\
\hline 158 & Sensitive & 24 & $10.1 \pm 1.5$ & $<0.0001$ & $<0.0001$ & 2011 & Maine \\
\hline 161 & Sensitive & 15 & $20.1 \pm 7.4$ & 0.0002 & 0.0675 & 2010 & New York \\
\hline 162 & Sensitive & 48 & $24.5 \pm 2.8$ & $<0.0001$ & 0.0510 & 2012 & Michigan \\
\hline 163 & Sensitive & 32 & $28.4 \pm 3.6$ & $<0.0001$ & 0.3728 & 2012 & Maine \\
\hline 164 & Sensitive & 37 & $41.1 \pm 2.9$ & $<0.0001$ & 0.1042 & 2012 & New York \\
\hline 165 & Sensitive & 19 & $15.8 \pm 2.9$ & $<0.0001$ & 0.0032 & 2012 & Massachusetts \\
\hline 166 & Sensitive & 36 & $4.26 \pm 1.9$ & $<0.0001$ & $<0.0001$ & 2012 & Maine \\
\hline 167 & Sensitive & 35 & $10.0 \pm 1.4$ & $<0.0001$ & $<0.0001$ & 2012 & Maine \\
\hline 168 & Sensitive & 23 & $4.5 \pm 1.1$ & $<0.0001$ & $<0.0001$ & 2012 & Maine \\
\hline 169 & Sensitive & 25 & $13.7 \pm 2.7$ & $<0.0001$ & 0.0002 & 2012 & Maryland \\
\hline 170 & Sensitive & 33 & $29.6 \pm 3.5$ & $<0.0001$ & 0.2034 & 2012 & New York \\
\hline 171 & Sensitive & 35 & $37.8 \pm 3.0$ & 0.0002 & 0.5294 & 2012 & New York \\
\hline 173 & Sensitive & 16 & $8.6 \pm 3.3$ & $<0.0001$ & 0.0002 & 2013 & Vermont \\
\hline 174 & Sensitive & 37 & $13.5 \pm 2.9$ & $<0.0001$ & $<0.0001$ & 2013 & Maine \\
\hline 175 & Sensitive & 26 & $28.3 \pm 5.1$ & 0.0003 & 0.2565 & 2013 & New York \\
\hline
\end{tabular}

a Designation number represents the identical $V$. inaequalis population screened for resistance to myclobutanil.

b Orchard classification was determined by comparing the distribution of difenoconazole sensitivity responses (isolate percent mean relative growth [\%RG] values) for a given $V$. inaequalis orchard population with standard orchard populations with and without practical resistance to myclobutanil using the KolmogorovSmirnov two-sample test in SAS (version 9.3; SAS Institute, Cary, NC). Red-sens = reduced sensitive.

${ }^{c}$ Orchard population mean percent growth of $V$. inaequalis isolates on medium amended with analytical-grade difenoconazole at $0.1 \mu \mathrm{g} \mathrm{ml}{ }^{-1}$ relative to that on nonfungicide medium (\%RG). Values are means and standard errors of $n$ isolates for each population, with five single-conidium colonies for each isolate.

${ }^{\mathrm{d}}$ Probability that the distribution of sensitivity responses for the orchard population in question is not significantly different from the standard orchard population with $(\mathrm{Pr}>$ Ksa resistant) or without $(\mathrm{Pr}>$ Ksa sensitive) practical resistance to myclobutanil. 
$V$. inaequalis with insensitivity to DMI fungicides has been found previously to occur over a limited distance (Gao et al. 2009), the arrival of reduced-sensitive isolates of $V$. inaequalis most likely took a number of years. Given the number of wild hosts and the age of the baseline orchard (greater than 15 years), it is plausible that isolates with reduced sensitivity originated from a commercial orchard managed with DMI fungicides several kilometers away.

Maine was the only state surveyed in which the majority of its $V$. inaequalis populations were sensitive to myclobutanil. Although fungicide use practices were no different than in orchards in New York and other New England states, other factors such as climate may have contributed to preservation of myclobutanil efficacy in Maine. Although little is known about the effect of extended low temperatures on pseudothecia survival and viable ascospore emergence, cessation of pseudothecia and ascospore development has been observed at or below temperatures of $0^{\circ} \mathrm{C}$. (Gadoury and MacHardy 1982). Indeed, extended subfreezing temperatures in Maine could result in reduced primary inoculum and, consequently, a lower absolute number of myclobutanil-resistant ascospores could have been released in the following spring. Marine et al. (2007) observed some reduced sensitivity to DMI fungicides when isolates of $V$. inaequalis were collected in July but not in cooler months of the spring. Another factor that may contribute to the greater number of sensitive populations in Maine is the relatively small orchard size
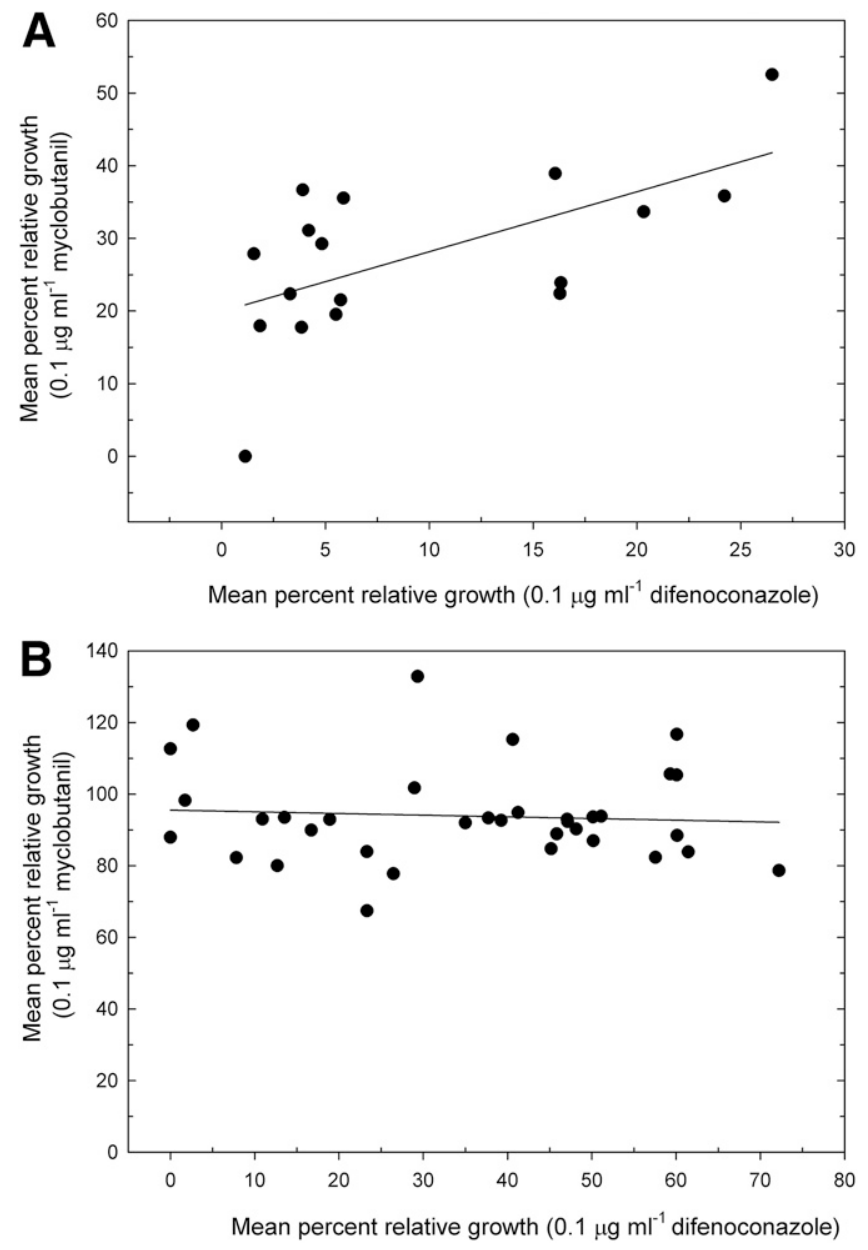

Fig. 2. Mean percent relative growth values of Venturia inaequalis isolates on difenoconazole at $0.1 \mu \mathrm{g} / \mathrm{ml}$ plotted against mean percent relative growth of those isolates on myclobutanil at $0.1 \mu \mathrm{g} / \mathrm{ml}$. Isolates were collected from $\mathbf{A}$, a baseline orchard or $\mathbf{B}$, a research orchard resistant to myclobutanil. A linear distribution function $\left[y=\left(y_{0}+a x\right)\right]$ was fitted to the isolate mean percent relative growth values for myclobutanil and difenoconazole. For the baseline orchard, the $R$ value was $0.610(n=17, P=0.0123)$. For the myclobutanil-resistant orchard, the $R$ value was $0.073(n=35, P=0.667)$. and low cultivar diversity within orchards (personal communication). Indeed, Pfeufer and Ngugi (2012) found that orchards smaller than 10 ha and those planted with fewer than 10 cultivars were significantly more sensitive to DMI fungicides.

In this study, the mean difenoconazole $\mathrm{EC}_{50}$ value for $44 \mathrm{New}$ York baseline isolates of $V$. inaequalis was determined to be $0.002 \mu \mathrm{g} / \mathrm{ml}$. This concentration was considerably lower than previously reported $\mathrm{EC}_{50}$ values for $V$. inaequalis baseline populations from Germany and Chile, which were 0.09 and $0.017 \mu \mathrm{g} / \mathrm{ml}$, respectively (Henríquez et al. 2011; Kunz et al. 1997). Similarly, the wildtype $V$. inaequalis isolates used in other DMI baseline studies in North America also had a relatively higher level of variability in DMI sensitivity (Henríquez et al. 2011; Smith et al. 1991) than the baseline population selected for this study. In the current study, minimum and maximum $\mathrm{EC}_{50}$ values of $V$. inaequalis isolates were separated by a factor of 45 , with a corresponding resistance factor of 4.5 (data not shown). These factors are much lower than those reported for other DMI baseline studies on $V$. inaequalis and other fungal pathogens (Henríquez et al. 2011; Kunz et al. 1997; Smith et al.1991; Spolti et al. 2014). The low frequency of isolates with reduced sensitivity to difenoconazole in our baseline population could have implications for the rate of development of resistance to difenoconazole. Within a given population, isolates with an $\mathrm{EC}_{50}$ value above the mean for the population should have a greater likelihood for survival when difenoconazole is applied, compared with isolates more sensitive to difenoconazole. In the presence of a DMI fungicide, selection for such isolates with reduced sensitivity could ultimately lead to practical resistance over time. Thus, the paucity of isolates with reduced sensitivity to difenoconazole in our New York baseline population may favor a delayed onset of resistance to difenoconazole.

Of the 36 orchard populations that were confirmed to be sensitive to difenoconazole, 24 were either resistant or had reduced sensitivity to myclobutanil. Similarly, in our research orchard with stable practical resistance to myclobutanil, we found that isolates of $V$. inaequalis from that orchard population were sensitive to difenoconazole in each of 5 years tested. These observations were in agreement with previous studies that found that difenoconazole demonstrated greater intrinsic activity compared with other DMI fungicides (Henríquez et al. 2011; Kunz et al. 1997; Pfeufer and Ngugi 2012; Thomas et al. 2012). Although varying degrees of intrinsic activity among the DMI fungicides have been widely documented for a number of plant-pathogenic fungi (Köller et al. 1991; Wong and Midland 2007; Ypema et al. 1997), cross-sensitivity within this class generally

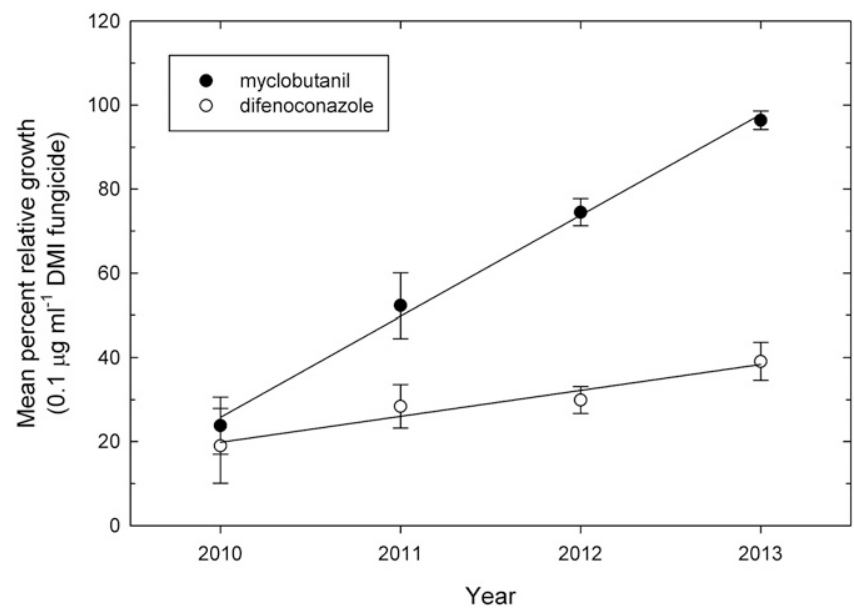

Fig. 3. Mean percent relative growth and standard errors of Venturia inaequalis isolates on myclobutanil (closed circles) or difenoconazole (open circles) at $0.1 \mu \mathrm{g} / \mathrm{ml}$ collected annually from a research orchard from 2010 to 2013. During each year, a minimum of 20 isolates of $V$. inaequalis were evaluated for sensitivity to each demethylation inhibitor (DMI) fungicide. Points where error bars did not overlap had significant differences in sensitivity between the two fungicides. 
has historically been observed in baseline populations (Hsiang et al. 1997; Karaoglanidis and Thanassoulopoulos et al. 2003; Köller et al. 1991). In the current study, a positive correlation in the responses of $V$. inaequalis isolates to myclobutanil and difenoconazole was observed when the isolates were collected from a baseline orchard. However, this degree of cross-sensitivity was not evident in a population that previously had extensive exposure and was resistant to myclobutanil. A similar inconsistency in DMI cross-sensitivity had been observed in Pyrenophora teres for populations collected from different locations (Peever and Milgroom 1993). A lack of crosssensitivity between two populations could be explained by differences in orchard microclimate, inherent differences in population composition (Xu et al. 2010), or type of management programs used. The absence of DMI cross-sensitivity for isolates in a myclobutanilresistant population of $V$. inaequalis could also result from different genetic components being involved in resistance development for the two fungicides. Indeed, several mechanisms, including overexpression of the target CYP51A1 gene (Schnabel and Jones 2001), point mutations within the CYP51A1 gene (Délye et al. 1997), and overexpression of energy-dependent drug efflux pumps (Nakaune et al. 1998), have all been previously implicated in DMI fungicide resistance. In-depth examination into the molecular biology of $V$. inaequalis isolates collected from the same population with varying levels of sensitivity to myclobutanil and difenoconazole would be needed to test for the involvement of different genetic mechanisms of resistance.

Applications of myclobutanil or difenoconazole were made to populations of $V$. inaequalis displaying practical resistance or sensitivity to myclobutanil to examine changes in the distribution of isolate sensitivities to DMI fungicides. Twenty-four applications of myclobutanil applied to a $V$. inaequalis population over six seasons did not further shift the distribution of isolates toward greater levels of myclobutanil resistance. Moreover, the population did not shift toward myclobutanil sensitivity following the cessation of myclobutanil applications. In other fungal pathogens of fruit, including Monilinia fructicola, a fitness penalty has been associated with isolates that have reduced sensitivity to DMI fungicides (Cox et al. 2007). Although fitness penalties for DMI resistance have not been documented in $V$. inaequalis, we still suspect that periods without myclobutanil use ( $>20$ years) could shift a population toward sensitivity. Indeed, populations of $V$. inaequalis formally resistant to dodine were recently found to be sensitive to the chemistry following

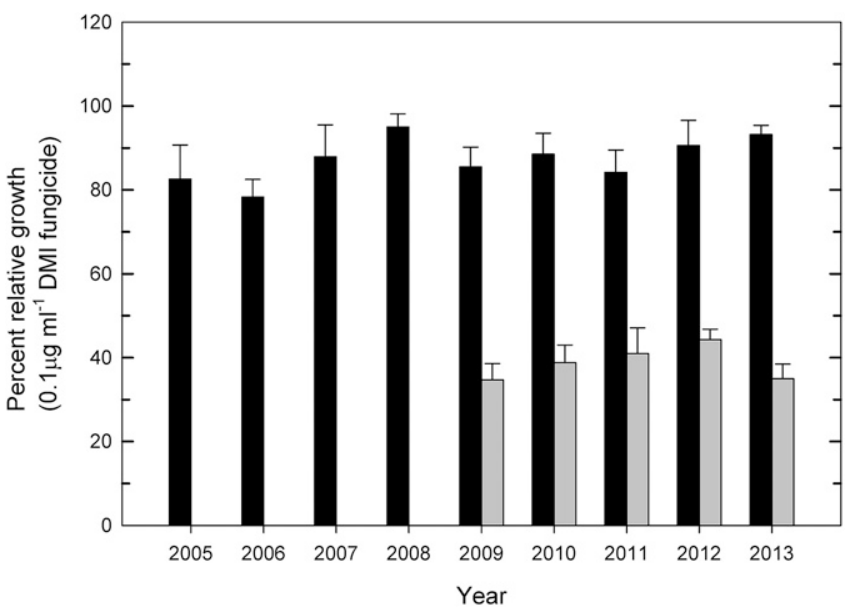

Fig. 4. Mean percent relative growth of Venturia inaequalis isolates collected from a research orchard from 2005 to 2013 to the demethylation inhibitor (DMI) fungicides myclobutanil (black bars) and difenoconazole (gray bars). Difenoconazole sensitivity was not evaluated from 2005 through 2008. From 2005 to 2010, myclobutanil was applied four times per season, and applications were discontinued in 2011. Number of isolates $(n)$ tested for sensitivity to myclobutanil or sensitivity to difenoconazole in each year were 2005: $n=30,2006: n=30,2007: n=30,2008: n=50,2009: n=$ 32, 2010: $n=29,2011: n=29,2012: n=35$, and 2013: $n=35$. the curtailment of dodine use within an orchard for more than 20 years (Cox et al. 2010).

In our research orchard of 'Empire' apple with a myclobutanilsensitive population of $V$. inaequalis, 16 applications of difenoconazole over a 4-year period resulted in increased population shifts toward myclobutanil and difenoconazole resistance. Interestingly, the level of resistance to myclobutanil in terms of the population mean increased at a steady rate of $25 \%$ RG per year compared with $6.7 \%$ $\mathrm{RG}$ for difenoconazole. Despite the discussion above about a lack of complete cross-sensitivity between myclobutanil and difenoconazole, we suspect that the field rate of difenoconazole may have quickly selected for isolates that were highly resistant to myclobutanil. Indeed, as a population becomes resistant to DMI fungicides, higher rates of a fungicide or applications of a more intrinsically active fungicide at an effectively similar rate may select for the most resistant members of a pathogen population (Lalancette et al. 1987). Although the population in our research orchard of 'Empire' apple was sensitive to myclobutanil in $2010,20 \%$ of isolates tested in the orchard had RG values greater than $60 \%$ (data not shown). Because individual isolates of $V$. inaequalis with resistance to myclobutanil were already present in the orchard, even a single season of applications from the more intrinsically active difenoconazole may have quickly selected for highly resistant members.

Overall, results of this study have shown that practical resistance to myclobutanil is present in populations of $V$. inaequalis throughout the major apple-production regions in the northeastern United States. Unlike other fungicide classes (i.e., benzimidazoles and QoIs) where, qualitative resistance resulted in a relatively rapid emergence of resistance ( $<10$ years of use) in the region, DMI fungicides like myclobutanil had been an essential component of apple scab management programs in the northeastern United States for more than 15 years. Although myclobutanil may no longer provide acceptable levels of apple scab control in most of the commercial orchards evaluated in this study, no orchard populations of $V$. inaequalis have practical resistance to difenoconazole. Still, caution should be exercised when applying difenoconazole in populations with resistance to myclobutanil, because such populations tend to have isolates with reduced sensitivity to difenoconazole.

\section{Acknowledgments}

This work was supported, in part, by funds appropriated to New York State Agricultural Experiment Station, Cornell University. We thank W. Köller and D. Parker for providing isolates, for training the authors on many of the techniques utilized in the microbiological assays of the study, and for providing useful advice on the analysis and interpretation of data; our collaborators who assisted in the collection of field samples and fungicide use histories for evaluated orchards, including J. Alicandro, P. Babcock, B. Baker, B. Bascombe, M. Belco, M. A. Bell, M. Biltonen, M. Borsick Herman, J. Bover, D. Breth, E. Brown, R. Bubier, J. Caroll, A. Clark, S. Clark, L. DeVoe, J. Dinardo, R. Drown, M. Ellis, M. Fargione, H. Faubert, H. Feller, M. Forrence, M. Forrence, M. Funk, Z. Goodband, D. Green III, A. Grobe, D. Hartley, L. Herring, A. Hill, C. Hodges, J. Ivison, C. Jaswell, E. Jensen, K. Karter, G. Koehler, E. Leadbeater, J. Lyman, A. Lynd, J. Matthews, J. Mitsiti, G. Morin, D. O'Connor, B. Olson, C. Petzoldt, D. Polseno, D. Rainer, D. Rosenberger, F. Santurri, R. Seem, M. Shannon, D. Simmons, B. Smith, R. Spitko, J. Steere, A. Sullivan, A. Teach, P. TenEyck, G. Thornton, D. Tower, F. Trail, B. Truncali, A. Tuttle, R. Wander, A. Wodehouse, S. Wood, M. Wright, K. Yoder, M. Zifchock, and S. Zonneville; and K. Abbot, M. Ellis, J. Freier, N. Gottschall, C. Lehman, C. K. Poon, M. Rosato, and K. Villani for their assistance in the collection and preparation of and evaluation of isolates.

\section{Literature Cited}

Beckerman, J. L., Sundin, G. W., and Rosenberger, D. A. 2015. Do some IPM concepts contribute to the development of fungicide resistance? Lessons learned from the apple scab pathosystem in the United States. Pest Manage. Sci. 71:331-342.

Braun, P. G., and McRae, K. B. 1992. Composition of a population of Venturia inaequalis resistant to myclobutanil. Can. J. Plant Pathol. 14:215-220.

Chapman, K. S., Sundin, G. W., and Beckerman, J. L. 2011. Identification of resistance to multiple fungicides in field populations of Venturia inaequalis. Plant Dis. 95:921-926.

Cox, K. D., Bryson, P. K., and Schnabel, G. 2007. Instability of propiconazole resistance and fitness in Monilinia fructicola. Phytopathology 97:448-453.

Cox, K. D., Villani, S. M., Ellis, M. A., Poon, C. K., and Craig-Kuhn, M. C. 2009 Evaluation of fungicides and application timing for control of powdery mildew and apple scab, 2008. Plant Dis. Manage. Rep. 3:PF038. Online publication. doi:10.1094/PDMR03 
Cox, K. D., Villani, S. M., and Jacon, G. 2010. Status of dodine resistance and possibilities for renewed use against Venturia inaequalis populations in the northeastern U.S. (Abstr.) Phytopathology 100:S27.

Cox, K. D., Villani, S. M., and Raes, J. J. 2013. Evaluation of fungicides for the control of apple scab and powdery mildew in an 'Empire'-'Jonagold' orchard with a DMI and QoI-resistant apple scab population, 2012. Plant Dis. Manage. Rep. 7:PF003. Online publication. http://www.plantmanagementnetwork.org/pub/ trial/pdmr/volume7/abstracts/pf003.asp

Délye, C., Laigre, F., and Corio-Costet, M.-F. 1997. A mutation in the $14 \alpha-$ demethylase gene of Uncinula necator that correlates with resistance to a sterol biosynthesis inhibitor. Appl. Environ. Microbiol. 63:2966-2970.

Frederick, Z. A., Villani, S. M., Cooley, D. R., Biggs, A. R., Raes, J. J., and Cox, K. D. 2014. Prevalence and stability of qualitative QoI resistance in populations of Venturia inaequalis in the northeastern United States. Plant Dis. 98:1122-1130.

Gadoury, D. M., and MacHardy, W. E. 1982. A model to estimate the maturity of ascospores of Venturia inaequalis. Phytopathology 72:901-904.

Gao, L., Berrie, A., Yang, J., and Xu, X. 2009. Within- and between-orchard variability in the sensitivity of Venturia inaequalis to myclobutanil, a DMI fungicide, in the UK. Pest Manage. Sci. 65:1241-1249.

Henríquez, J. L., Sarmiento V. O., and Alarcón, P. 2011. Sensitivity of Venturia inaequalis Chilean isolates to difenoconazole, fenarimol, mancozeb, and pyrimethanil. Chil. J. Agric. Res. 71:39-44.

Hildebrand, P. D., Lockhart, C. L., Newbery, R. J., and Ross, R. G. 1988. Resistance of Venturia inaequalis to bitertanol and other demethylationinhibiting fungicides. Can. J. Plant Pathol. 10:311-316.

Hsiang, T., Yang, L., and Barton, W. 1997. Baseline sensitivity and crossresistance to demethylation-inhibiting fungicides in Ontario isolates of Sclerotinia homoeocarpa. Eur. J. Plant Pathol. 103:409-416.

Jobin, T., and Carisse, O. 2007. Incidence of myclobutanil- and kresoxim-methylinsensitive isolates of Venturia inaequalis in Quebec orchards. Plant Dis. 91: 1351-1358.

Jones, A. L. 1981. Fungicide resistance: Past experience with benomyl and dodine and future concerns with sterol inhibitors. Plant Dis. 65:990-992.

Karaoglanidis, G. S., and Thanassoulopoulos, C. C. 2003. Cross-resistance patterns among sterol biosynthesis inhibiting fungicides (SBIs) in Cercospora beticola. Eur. J. Plant Pathol. 109:929-934.

Köller, W. 1991. Fungicide resistance in plant pathogens. Pages 679-720 in: CRC Handbook of Pest Management in Agriculture, Vol. 2, 2nd ed. D. Pimentel, ed. CRC Press, Boca Raton, FL.

Köller, W., Parker, D. M., and Reynolds, K. L. 1991. Baseline sensitivities of Venturia inaequalis to sterol demethylation inhibitors. Plant Dis. 75: 726-728.

Köller, W., Parker, D. M., Turechek, W. W., Avila-Adame, C., and Cronshaw, K. 2004. A two-phase resistance response of Venturia inaequalis populations to the QoI fungicides kresoxim-methyl and trifloxystrobin. Plant Dis. 88:537-544.

Köller, W., and Wilcox, W. F. 1999. Evaluation of tactics for managing resistance of Venturia inaequalis to sterol demethylation inhibitors. Plant Dis. 83:857-863.

Köller, W., and Wilcox, W. F. 2001. Evidence for the predisposition of fungicideresistant phenotypes of Venturia inaequalis to a preferential selection for resistance to other fungicides. Phytopathology 91:776-781.

Köller, W., Wilcox, W. F., Barnard, J., Jones, A. L., and Braun, P. G. 1997. Detection and quantification of resistance of Venturia inaequalis populations to sterile demethylation inhibitors. Phytopathology 87:184-190.

Kunz, S., Deising, H., and Mendgen, K. 1997. Acquisition of resistance to sterol demethylation inhibitors by populations of Venturia inaequalis. Phytopathology 87:1272-1278

Lalancette, N., Hickey, K. D., and Cole, H., Jr. 1987. Effects of mixtures of benomyl and mancozeb on the buildup of benomyl-resistant Venturia inaequalis. Phytopathology 77:86-91.

Lesniak, K. E., Proffer, T. J., Beckerman, J. L., and Sundin, G. W. 2011. Occurrence of QoI resistance and detection of the G143A mutation in Michigan populations of Venturia inaequalis. Plant Dis. 95:927-934.

MacHardy, W. E. 1996. Apple Scab-Biology, Epidemiology, and Management. American Phytopathological Society, St. Paul, MN.

MacHardy, W. E., and Gadoury, D. M. 1989. A revision of Mills' s criteria for predicting apple scab infection periods. Phytopathology 79:304-310.
MacHardy, W. E., Gadoury, D. M., and Gessler, C. 2001. Parasitic and biological fitness of Venturia inaequalis: Relationship to disease management strategies. Phytopathology 85:1036-1051.

Marine, S. C., Schmale, D. G., and Yoder, K. S. 2007. Resistance to myclobutanil in populations of Venturia inaequalis in Winchester, Virginia. Online publication. Plant Health Prog. doi:10.1094/PHP-2007-1113-01-RS

Nakaune, R., Adachi, K., Nawata, O., Tomiyama, M., Akutsu, K., and Hibi, T. 1998. A novel ATP-binding cassette transporter involved in multidrug resistance in the phytopathogenic fungus Penicillium digitatum. Appl. Environ. Microbiol. 64:3983-3988.

O'Leary, A. L., Jones, A. L., and Ehret, G. R. 1987. Application rates and spray intervals for apple scab control with flusilazol and pyrifenox. Plant Dis. 71 623-626.

Peever, T. L., and Milgroom, M. G. 1993. Genetic correlations in resistance to sterol biosynthesis-inhibiting fungicides in Pyrenophora teres. Phytopathology 83:1076-1082.

Pfeufer, E. E., and Ngugi, H. K. 2012. Orchard factors associated with resistance and cross resistance to sterol demethylation inhibitor fungicides in populations of Venturia inaequalis from Pennsylvania. Phytopathology 102: 272-282.

Rosenberger, D. A., Cox, K. D., Rugh, A., Villani, S. M., and Frederick, Z. 2010 Apple scab management options for high inoculum orchards. N. Y. Fruit Q. 20: 9-13.

Schnabel, G., and Jones, A. L. 2001. The 14 $\alpha$-Demethylase (CYP51A1) gene is overexpressed in Venturia inaequalis strains resistant to myclobutanil. Phytopathology 91:102-110.

Schwabe, W. F. S., Jones, A. L., and Jonker, J. P. 1984. Greenhouse evaluation of the curative and protective action of sterol-inhibiting fungicides against apple scab. Phytopathology 74:249-252.

Smith, F. D., Parker, D. M. and Köller, W. 1991. Sensitivity distribution of Venturia inaequalis to the sterol demethylation inhibitor flusilazole: Baseline sensitivity and implications for resistance monitoring. Phytopathology 81 392-396.

Spolti, P., Del Ponte, E. M., Dong, Y., Cummings, J. A., and Bergstrom, G. C. 2014. Triazole sensitivity in a contemporary population of Fusarium graminearum from New York wheat and competitiveness of a tebuconazoleresistant isolate. Plant Dis. 98:607-613.

Stanis, V. F., and Jones, A. L. 1985. Reduced sensitivity to sterol-inhibiting fungicides in field isolates of Venturia inaequalis. Phytopathology 75:1098-1101.

Stenzel, K. 2014. FRAC SBI Working Group. Online publication. http://www.frac.info/ working-group/sbi-fungicides

Szkolnik, M. 1981. Physical modes of action of sterol-inhibiting fungicides against apple diseases. Plant Dis. 65:981-985.

Thomas, A., Langston, D. B., Jr., and Stevenson, K. L. 2012. Baseline sensitivity and cross-resistance to succinate-dehydrogenase-inhibiting and demethylationinhibiting fungicides in Didymella bryoniae. Plant Dis. 96:979-984.

Turechek, W. W., Heidenreich, M. M., and Heidenreich, G. 2005. Evaluation of captan fungicide programs for management of apple scab in a benzimidazole and DMI-resistant orchard, 2004. Fungic. Nematicide Tests 60:PF027. Online Publication. doi:10.1094/FN60

Villani, S. M., and Cox, K. D. 2011. Characterizing fenbuconazole and propiconazole sensitivity and prevalence of 'Mona' in isolates of Monilinia fructicola from New York. Plant Dis. 95:828-834.

Villani, S. M., and Cox, K. D. 2014. Heteroplasmy of the cytochrome b gene in Venturia inaequalis and its involvement in quantitative and practical resistance to trifloxystrobin. Phytopathology 104:945-953.

Wong, F. P., and Midland, S. L. 2007. Sensitivity distributions of California populations of Colletotrichum cereale to the DMI fungicides propiconazole, myclobutanil, tebuconazole, and triadimefon. Plant Dis. 91:1547-1555.

Xu, X.-M., Gao, L.-Q., and Yang, J.-R. 2010. Are insensitivities of Venturia inaequalis to myclobutanil and fenbuconazole correlated? Crop Prot. 29:183-189.

Yoshimura, M. A., Luo, Y., Ma, Z., and Michailides, T. J. 2004. Sensitivity of Monilinia fructicola from stone fruit to thiophanate-methyl, iprodione, and tebuconazole. Plant Dis. 88:373-378.

Ypema, H. L., Ypema, M., and Gubler, W. D. 1997. Sensitivity of Uncinula necator to benomyl, triadimefon, myclobutanil, and fenarimol in California. Plant Dis. 81:293-297. 